\title{
Here to Stay: Cyber Communication as a Complement in Social Work Practice
}

\author{
Mishna, Faye; Bogo, Marion; Root, Jennifer; Fantus, Sophia
}

Version Accepted Manuscript

Citation Mishna, F., Bogo, M., Root, J., \& Fantus, S. (2014). Here to Stay: Cyber (published version) communication as a complement in social work practice. Families in Society, 95(3), 179-186. DOI: 10.1606/1044-3894.2014.95.2.

Publisher's Statement Copyright 2014 by Alliance for Strong Families and Communities

How to cite TSpace items

Always cite the published version, so the author(s) will receive recognition through services that track citation counts, e.g. Scopus. If you need to cite the page number of the TSpace version (original manuscript or accepted manuscript) because you cannot access the published version, then cite the TSpace version in addition to the published version using the permanent URI (handle) found on the record page. 


\title{
Here to Stay: Cyber Communication as a Complement in Social Work Practice
}

\author{
Faye Mishna, Professor and Dean \\ Factor-Inwentash Faculty of Social Work \\ University of Toronto \\ 246 Bloor Street West \\ Toronto, Ontario M5S 1V4 \\ f.mishna@utoronto.ca \\ Phone: (416) 946-5494 \\ Fax: (416) 978-7072 \\ Marion Bogo, Professor \\ Factor-Inwentash Faculty of Social Work \\ University of Toronto \\ 246 Bloor Street West \\ Toronto, Ontario M5S 1V4 \\ Jennifer Root, $\mathrm{PhD}$ Student \\ Factor-Inwentash Faculty of Social Work \\ University of Toronto \\ 246 Bloor Street West \\ Toronto, Ontario M5S 1V4 \\ Sophia Fantus, PhD Student \\ Factor-Inwentash Faculty of Social Work \\ University of Toronto \\ 246 Bloor Street West \\ Toronto, Ontario M5S 1V4
}

\section{Abstract}

The digital age has revolutionized how individuals interact. The number of users has increased exponentially, along with expanding local and global networks and opportunities for learning, entertainment, and support. Most recently, cyber communication is becoming an important part of face-to-face social work practice as an administrative and therapeutic exchange between practitioners and clients, with both benefits and challenges. The purpose of this paper is to 
present results of a study that utilized grounded theory to explore the application and adaptation of information and communication technology (ICT) in traditional clinical social work practice within organizations and private practice. The overwhelming finding was that it is no longer possible not to engage in the use of ICT. We discuss implications for practice.

\section{Introduction}

The dramatic increase of information and communication technology (ICT) has transformed social networking (Migone, 2013; Perron, Taylor, Glass, \& Margerum-Leys, 2010). The digital age has revolutionized how individuals of all ages interact. Not only is there tremendous accessibility and ease of online messaging, but there has been a transformational emergence and popularity of social networking sites, such as Twitter, Facebook, Tumblr, and Instagram. The number of users has increased exponentially, along with expanding local and global networks and opportunities for learning, entertainment, and support (Blais, Craig, Pepler, \& Connolly, 2008). Most recently, cyber communication is becoming a part of traditional face-to-face social work practice, as an administrative and therapeutic exchange between practitioners and clients (Author, 2012). Cyber correspondences in conjunction with face-to-face practice offer benefits and evoke questions. In 2012 we reported on the findings of phase one of a study examining how practitioners understood and used ICT in their traditional practice. Recognizing the rapid growth and increasingly ubiquitous use of ICT, we conducted phase two of the study to further examine the clinical, practical, and ethical benefits and issues of ICT in conjunction with social work practice and its implications for the therapeutic exchange. In this paper we report and discuss the findings of phase two of the study.

\section{Online Mental Health Services}


Mental health practitioners including social workers, psychologists, and psychiatrists have responded to the greater accessibility of ICT with online therapy programs (Wright, 2002). Online therapy, or e-counseling, is offered through synchronous or asynchronous communication, structured within firewalls and encryption passwords to protect the privacy of service users (Murphy, Parnass, Mitchell, Hallett, Cayley, \& Seagram, 2009). Studies examining e-therapy/e-counseling tend not to distinguish among mental health fields although, of $73 \mathrm{e}-$ therapy web sites that were surveyed, 38.4 percent listed one or more MSW social workers as providing therapy and social workers were found to use computer videoconferencing more than non-social workers (Santhiveeran \& Grant, 2006). There is limited social work literature on the utilization of e-therapy/e-counseling (Author, 2013b; Santhiveeran, 2004). The extant literature mainly discusses the implications of therapy using ICT in social work practice (McCarty \& Clancy, 2002; Menon \& Miller-Cribbs, 2002).

Ethical and legal issues related to online therapy have been examined, including licensure issues, technology failures, potential miscommunication, lost correspondence, and lack of privacy (Reamer, 2013; Rummell \& Joyce, 2010). Extending access to persons with disabilities, social anxiety, or in rural or underserviced areas, there is evidence that online therapy is effective, with the establishment of strong working relationships and successful outcomes, often comparable to in-person therapy (D'Arcy \& Stiles, 2009; Holmes \& Foster, 2012).

\section{Traditional Social Work Practice and ICT}

Distinct from online therapy, ICT has started to affect practice, utilized in conjunction with face-to-face social work practice. Our research shows that ICT has influenced how practitioners communicate with clients and has begun to be a supplementary mode of contact (Author, 2012). ICT includes the use of tools such as email and text-based communication through handheld 
devices and social networking sites (Mattison, 2012; Reamer, 2013). Benefits include facilitating a practitioner's administrative responsibilities (Finn, 2006; Author, 2012), assisting clients to communicate and engage with the practitioner (Bradley \& Hendricks, 2009), providing time to reflect on previous sessions (Wright, 2002), and helping practitioners forecast issues and structure the next session to create mutually shared goals (Perron, et al., 2010).

Despite benefits, using ICT introduces ethical and clinical issues (Author, 2013a; Mattison, 2012; Author, 2012, 2013b; Reamer, 2013). According to Reamer (2013), “although social workers continue to pay close attention to many of the same ethics concepts that defined the profession in its earliest years, the ways in which these concepts manifest themselves have changed dramatically as a result of significant societal and technological change" (p.15). Reamer (2013) and Mattison (2012) both draw attention to the risks of employing ICT in clinical practice, associated with ethical issues such as confidentiality and boundaries. As texting, email and social networking sites become increasingly popular among individuals of all ages, Reamer (2013) cautions that clients and practitioners must be mindful of online access and sharing of personal information and stresses that information sent over non-encrypted networks cannot be guaranteed confidentiality. Mattison (2012) similarly notes the need for passwords or encryption software to counteract risks related to confidentiality, such as authorized or unauthorized persons potentially gaining access to printed, deleted or received messages sent online.

The use of ICT in social work practice may also lead to boundary crossings and violations. Due to the 24-hour accessibility of online networking, Reamer (2013) directs practitioners to be prudent in how and when they respond online to clients. Likewise, Mattison (2012) explains that response times and the informal and personal nature of text-based communication and loss of social cues may increase the risk of dual relationships, conflict of interest, or unclear boundaries. 
Mattison (2012) focuses on establishing regulatory practices for practitioners, stressing the need to minimize legal concerns through an informed consent that provides clients information on the risks and benefits of ICT in clinical practice. Mattison (2012) concludes that with a lack of professional standards and guidelines to support the ethical use of ICT, social workers must manage ethical and clinical challenges and are thus responsible for setting guidelines, including identifying topics that are appropriate to discuss through ICT, response times, the parameters of the relationship, and the limitations to privacy and confidentiality. Reamer (2013) similarly recommends an informed consent, which highlights risk management strategies such as the difficulty communicating non-verbal cues, information on encrypted servers, and the potential for misunderstandings or conflict over text. Reamer (2013) contends that social workers who use ICT have a duty to become familiar with the risks and benefits, as well as with current research.

Despite increased ICT use in face-to-face clinical practice, there is a lack of scholarly work on implications for practice (Clough \& Casey, 2011). Scholarly work on ICT and mental health has examined smart phone applications and texting as supplementary intervention tools for specific populations. In conjunction with traditional practice, practitioners use technology to monitor and manage psychological symptoms, provide homework assignments, remind clients of upcoming appointments, track treatment progress, and follow-up after termination (Eonta, Christon, Hourigan, Ravindran, Vrana, \& Southam-Gerow, 2011; Epstein \& Bequette, 2013). ICT, in this regard, has been used as a support to evidence-based treatment, most frequently employed to enhance cognitive behavioral therapy for individuals coping with depression, anxiety, and obsessive compulsive disorder (Boschen \& Casey, 2008; Eonta et al., 2011).

Literature on ICT and face-to-face practice, although relevant to social work, has mainly been conducted in psychology or general mental health counseling. Consequently, there is a 
dearth of scholarly work on how the increasing use of ICT has filtered into social work practice in contrast to its uses as a direct treatment method. The majority of research on ICT and social work has examined online therapy, rather than ICT used in conjunction with face-to-face practice. This paper contributes to the social work literature by examining the complementary use of ICT in face-face social work practice, based on practitioners' identification and articulation of their ongoing attempts to address this rapidly evolving dimension in practice.

\section{Social Work Code of Ethics}

When ethical or clinical challenges arise, the Code of Ethics is an important framework to guide social work practitioners in identifying, navigating, and resolving dilemmas and conflict. The National Association of Social Workers (NASW) and the Association of Social Work Boards (ASWB) have instigated a conversation regarding the use of ICT, both for online therapy programs and when utilized in conjunction with face-to-face practice. There is acknowledgement in the document, entitled Standards for Technology and Social Work Practice, that technology is altering social work practice and creating new approaches to mental health services and ways to obtain information (NASW, 2005). The established standards serve as a guide for social workers who incorporate ICT into their services, assisting them to monitor and manage their behavior. These standards also direct social workers on how best to inform clients, government regulatory bodies, insurance carriers, and others about the professional standards related to technology use in social work practice (NASW, 2005). Standards addressed in this document include competent practice, accessibility, cultural competence, privacy and confidentiality, risk management, administrative practice, as well as research and supervision.

As ICT use continues to increase dramatically across all age groups, the frequency and ease of these online correspondences become an inevitable component of face-to-face social work 
practice. Practitioners have a responsibility to be proficient, enhancing their knowledge, gaining skills related to text-based language and computer proficiency, and remaining informed about research, literature, and emerging ethical values and standards (Betteridge, 2012; Bradley \& Hendricks, 2009; Mattison, 2012; Author, 2012; Reamer, 2013).

\section{Method}

\section{Research Questions}

This qualitative study, carried out in two phases, focused on characterizing the nature and scope of e-based communication usage among social work practitioners and administrators, in the context of traditional face-to-face practice. The authors relied on the following questions to guide this study: how do practitioners use ICT to interact with clients?; and, what are the clinical, practical, ethical, and legal issues associated with the use (or not) of ICT in practice?

\section{Research Design}

In 2010 we began examining how cyber communication has "crept" into traditional face-toface practice and conducted focus groups and interviews with experienced practitioners and executive directors and managers. The results of phase one of the research exploring the nuanced usage of various forms of electronic communication were published (Author, 2012). Informed by these phase one findings, in phase two of the research, we examined the continued application and adaptation of ICT in clinical social work practice within organizations and private practice in a large metropolitan area in Ontario, Canada.

Grounded theory (Charmaz, 2006), designed to attend to qualitative analyses of interview data particularly text/transcript based analysis, was used as the primary methodological framework throughout the design, data collection, and analysis. While the over-arching purpose of conducting a grounded theory study is to develop a substantive theory or conceptual 
understanding of the research problem, this study utilized analytic techniques consistent with constructivist grounded theory to examine the deeper, subjective meanings and experiences of participants. While traditional grounded theory studies ideally culminate in an "abstract theoretical understanding of the studied experience" (Charmaz, 2006, p. 4), our primary objective was to illustrate and describe the 'data grounded' experiences of social work practitioners and administrators.

\section{Study Participants}

Between 2010 and 2013, 42 participants were interviewed in two phases based on theoretical sampling. Of the 42 participants, 29 were female and 13 were male, ranging in age from their mid-20s to mid-60s. All participants held MSW degrees and all were practicing social workers or administrators. The participants represented diverse practice fields, including health, mental health, education, and child and family. Their practice experience ranged from two to over 20 years. The University of Toronto's Research Ethics Board approval was received prior to data collection in both phases of the study.

Initial recruitment in each phase relied on several purposive sampling approaches including agency-based sampling, targeted email recruitment, and snowball sampling (Patton, 1990). Participants were recruited through email advertisements sent to the social work provincial professional association members located in the area (approximately 700), and to the social work school's partner agencies, alumni, and internal listservs. Interested participants were asked to contact a member of the research team. Participants were not reimbursed for their participation.

Phase one took place in 2010 and 2011 and included 15 participants characterized as ‘experienced practitioners'. Criteria to participate comprised: 1) possession of a Bachelor of Social Work or Master of Social Work degree; 2) registered with the Provincial Regulatory 
Body; 3) currently employed in a practice setting that involves working directly with agency clients or in private practice; and 4) reside in the Greater Metropolitan Area. In Phase one (2011) we also interviewed 11 participants who were 'administrators', including executive directors and managers of social service organizations.

In 2013, phase two of the study, 16 participants described as 'young and new practitioners' were interviewed. Additional criteria for this group of practitioners included being less than 35 years to ensure a younger cohort, considered relevant when examining ICT use, and having practiced in social work for fewer than 5 years. In addition, nine of the original participants in phase one who were practitioners were re-interviewed in 2013 (phase two). Consistent with grounded theory methodology, theoretical sampling in phase two was based on emerging concepts and the need to explore new ideas and questions arising from the data in phase one.

\section{Data Collection and Analysis}

The researchers facilitated a 1.5 to 2 hour focus group or in-depth interview hosted at the Social Work school. Focus groups and interviews were digitally recorded and transcribed verbatim, producing a transcript-based source of data. Analysis of interviews $(\mathrm{n}=17)$ and focus groups (10 groups; $n=34$ ) (note 9 participants were interviewed in both phases of the study) revealed a number of clinical, practical, ethical, and legal issues arising between social work practitioners and clients.

Simultaneous data collection and analysis occurred throughout both phases of the study. In an effort to remain as close to the data as possible, the lead researchers and a team of trained doctoral students met frequently to refine initial codes, clarify emerging themes, and discuss findings. As new questions arose, the need for sampling among specific cohorts of practitioners became evident. These distinct groups of practitioners were thus sought in order to further refine 
and deepen analysis. In fact, the impetus for re-interviewing the initial group of participants (i.e., the 'experienced practitioners') was based on questions emerging from the data analysis. Exploring emerging ideas with the initial group of participants provided a unique opportunity to not only strengthen the rigour and conceptual depth of the study findings, but to also capture new information (i.e., potential shifts in thinking) about the research questions.

The main analytic tools used to interpret and analyze the data in this study included 1) constant comparison of data across participants, 2) negative case analysis, 3) abductive coding based on Charmaz's initial, focused, and axial processes, and 4) memo writing. Comparing conceptual ideas across participants, codes and categories were developed using initial, focused, and axial levels of coding. Initial line-by-line coding was used to give temporary labels to a general phenomenon before moving into focused phases of coding which resulted in more enduring and analytical categories. Finally, axial phases of coding produced higher order categories and themes, which are explored fully in the findings.

\section{Findings}

To understand the context of findings of phase two of the study, we first note the themes that emerged in phase one and then discuss the findings of phase two. Phase one themes were: 1) client driven practice, 2) Pandora's box, 3) ethical grey zone, and 4) permeable boundaries (Author, 2012). Core elements of the work that were influenced included boundaries, disclosure of practitioner and client information, the therapeutic relationship, ethical and legal issues and dilemmas, and policies and procedures. In phase two, results indicate that traditional face-to-face social work practice has been transformed by ICT, with three main new themes emerging, which are presented below: 1) recognizing the therapeutic effects of cyber communication;2) boundaries in the ever-changing digital world; and 3) ethical grey zone. 


\section{Recognizing Therapeutic Effects}

Three years later, the experienced practitioners who had originally participated in phase one had changed in how they understood and used ICT. They described "shifting with the times," becoming deliberate in their use in contrast to their previous reactivity to client communication. They reflected on their use of ICT to "learn what works and what doesn't work." They posed questions such as "how do I educate my instincts?", "how is this meaningful to my clients?" and "how will this impact my personal life?"

Some of the 'young and new practitioners' approached the use of ICT differently from the experienced practitioners, assuming the benefit of ICT in social work practice: "it allows for easier access, frequent check-ins." As one practitioner explained, "why not help clients gain easier access to service and support what is easy for them - it takes two seconds to send a text?"

The executive directors and managers of social service organizations recognized the ubiquitous nature of the ascending digital world including the potential therapeutic benefits. One respondent described an acute awareness of "the shift in communication that has gone on, especially among adolescents. It's not pick up the phone and call them anymore, it's texting." According to another respondent, "texting does allow somebody to communicate some immediate concerns or issues that might have to be dealt with."

The phase one findings indicated that the experienced practitioners considered ICT beneficial for administrative purposes such as scheduling appointments and conveying information about resources. It became evident in phase two of the study that these practitioners now found ICT to also provide a new dimension in their practice, offering continuity of the relationship through extending the session. According to respondents, "for this client knowing she can connect with me on email is very meaningful. Someone is hearing her. She has found 
someone she can trust"; "Clients take strength in feeling they are connected to you." This new dimension also was a way to help clients process their thoughts and emotions and to selfregulate. One practitioner observed, "some clients like to write their thoughts after the session. It helps them process and reflect on issues." Another noted, "They're emailing me to say 'I need to share this with you.' It takes a bit of a burden off their shoulders. The stress and the anxiety of whatever they're suffering can be alleviated or decreased knowing that 'okay, I've shared, and I am able to now let this go until I see xxx."”

The 'young and new' practitioners also saw therapeutic benefits in the use of text and email. One noted the effectiveness of ICT in relationship building with hard-to-engage adolescents: "It supports that initial ability to engage and build rapport, which clients really respect and appreciate." Similar to the experienced practitioners 'young and new' practitioners recognized the benefit of writing and sharing with the worker: "Given her anxieties it gives her a venue to help her organize herself, to get all of her thinking and expression together." 'Young and new' practitioners reflected that email communication provided "flexibility for clients, they are not penned in by office hours... when she has a need to just reach out and connect, she knows that she can kind of vent into an email and that I'll respond the next day."

One 'young and new' practitioner demonstrated that online communication can show "small acts of caring, such as 'liking' a client's Facebook status if they write about a good day; it shows I am thinking about and there for them without having to say anything." This practitioner also gained important client information: "Sometimes I see statuses that are a little questionable or raise safety concerns and I will comment or send a message to check in with the client." Along this line of assessing client issues based on the cyber communication, another 'young and new' 
practitioner stated, "you're assessing for what's in the email because you still have that obligation... are they saying they're going to harm someone else or harm themselves?"

The executive directors and managers recognized that the use of ICT represents an innovation in practice. They appreciated the complexities of supporting the exploration by practitioners in using ICT. For instance, one respondent articulated, "I want social workers to think, to say 'it's about my client, and how am I going to innovate?' So if we want that innovation then we don't need to tie their hands down with rules."

\section{Addressing Boundaries in the Ever-Changing Digital World}

It emerged that in the three years since participating in phase one the experienced practitioners had begun to include discussion of ICT use in their initial sessions, thereby setting the frame, as demonstrated by the following quotation: "In the initial session I tell them what to expect regarding appointment reminders, when I will respond to emails, what type of responses

they will get, for example, acknowledgement but not in depth discussion of issues." Practitioners had become acutely aware of the radical change in expectations due to ICT. Indeed, some 'young and new' practitioners discussed the expectations by young people today that their texts to others would be answered "within minutes." The experienced practitioners had begun to anticipate this new expectation with clients. For instance, one respondent "explains in a clear, kind, emotionally present way that I know there are times when the client may want to reach me and while I would like to be available I cannot be at all times." The experienced practitioners recognized the ongoing need to address boundaries: "I revisit my boundaries as many times as I have to."

Some 'young and new' practitioners seemed to seamlessly integrate technology into their practice. One respondent, for example, stated, "we still have to maintain that basic of 'meet the client where they're at'. And if they're texting and emailing at 11 at night because that's when 
they can, that's what we work with." While valuing ICT in their work, other 'young and new' practitioners noted however, that "it makes it a little bit stickier to keep the professional boundaries." Some maintain boundaries with a phone and a Facebook/Twitter account they use only for work. They explain to adolescent clients, "While I'm very friendly, my role is not to be your friend, but to help you find friends." Similar to the experienced practitioners they stressed the importance of "transparency about where the boundaries lie" and the need to make it clear to clients that they are only available through these methods during "office hours". Practitioners stressed the importance of the agency providing 'after hour' emergency services. They also spoke about the necessity of clarifying what were appropriate conversations using technology and those more appropriate in face-to-face interviews. It also emerged that for some of the 'young and new practitioners' their understanding of the scope of ICT gave them an appreciation of how vulnerable, exposed, and unsafe they could be. For instance, one explained that a client from a former job may 'learn' that they are connected to a program with a Facebook page or Twitter account, "so it's not always that clean and that easy to maintain our own privacy."

The executive directors and managers felt responsible to allow practitioners room to be flexible yet were concerned that workers be protected. One respondent stated, "We don't want people to be on call 24 hours a day but we're in a field where sometimes we go above and beyond on weekends, in the evenings because of the nature of the work." Another stated, "You want to be responsive but you don't want to commit to a responsiveness that you can't deliver."

\section{Ethical Grey Zone}

Variations in policies across organizations were reported. Some were described as having explicit procedures and guidelines regarding cyber correspondence with clients and their 
families, while others were depicted as having vague policies. According to participants, agencies are increasingly beginning to use secure servers.

A major theme that emerged with the 'young and new' practitioners was their feeling "frustrated and constrained" by organization policy. According to one participant for instance, "We are often in situations where we have to make judgment calls that are more ethical or that have to do with our own personal and professional boundaries. And it could be different for different people in different scenarios. Blanket policies don't work. It's context specific." Still, when rejecting a request, one 'young and new' practitioner appreciated and "fell back on agency policy that clinicians are not allowed to be Facebook friends with clients".

The executive directors and managers stressed the challenge of both needing policies and recognizing the importance of not developing policies that are premature or too restrictive. As one respondent reflected, "right now I want to encourage exploration, and you can't encourage exploration with a million 'don't do this'. We're in exploration mode and within a couple of years will end up with a policy. Policy might limit things that, with more experience, you might say we can do that, we can find a way around that. We're learning about policy though.” Another respondent observed, "Many organizations and mine in particular, love to manage by policy. You have to be standards and guidelines based, so you have to look at best practice, at evidence."

Experienced practitioners identified an issue that arises in working with professionals such as lawyers and teachers. For example, a respondent expressed concern about confidentiality "when reports are sent by other professionals via email without locking the document." Another practitioner who was clear about not being available after hours described receiving late night 'panicked' texts/emails from others who worked with the client. Some experienced practitioners tried to educate clients about their vulnerability due to the lack of privacy, particularly in cases 
involving legal matters such as custody and access issues. As one respondent said, "I am ever increasingly mindful of my duty to be concerned about client vulnerability in this aspect.”

'Young and new' practitioners also expressed concerns about clients' potential vulnerability: "With emails,... it could be disseminated. We're lucky that we haven't had any problems because it's very likely." As with experienced practitioners they noted that since emails of any substance are printed and become part of the file, "when a client is involved with the legal system I would never respond to an email with important information - the case notes could be subpoenaed."

\section{Limitations}

Participation was voluntary and self-selected suggesting the need to be cautious in generalizing findings to practitioners. Another limitation is the focus from the perspectives of practitioners, executive directors and managers. Research is needed to compare the perspectives of clients with practitioners and managers. The findings correspond with the literature however, and offer insight into the increasing use of ICT in clinical social work practice.

\section{Discussion and Implications for Practice}

This paper presents the findings of phase two of a study on the use of ICT in face-to-face social work practice. In phase one we concluded, "Just as cyber technology has shaped how people of all ages communicate, it has revolutionized the communication of practitioners and clients, even those engaged in traditional face-to-face therapy" (Author, 2012, p. 283). In phase two it is clear that ICT is here to stay and it is no longer possible not to engage in the use of ICT. The experienced practitioners, the young and new practitioners and the executive directors and managers increasingly accept ICT as an inevitable complement in practice.

Three years later, the experienced practitioners had shifted in their responses, from feeling reactive and highly cautious, to feeling more comfortable in using ICT, a change likely due in 
part to the exponential growth of handheld devices. Participants recognized that using ICT is a novel innovation with potential benefit, especially as it provides continuity in the relationship. Participants tried to develop understanding and competence through reflective practice. They considered how they could adapt ethical and clinical standards to the new reality and developed their own practice wisdom and deliberate approach. Practices included initially orienting clients regarding use of ICT in the treatment, using informed consent, defining boundaries, and educating clients about their potential vulnerability regarding appropriate content for ICT. This development of practice contrasts with the recommendations in the literature that social workers educate themselves on the use of ICT through training and using practice-based research.

A hallmark of social work is the ecological systems framework, incorporating the reciprocal contributions of all levels of a person's environment (Bronfenbrenner, 1979; Gitterman \& Germain, 2008). Several scholars have adapted this framework to keep pace with the digital revolution (Johnson \& Puplampu, 2008; Johnson, 2010; Martin, 2013; Martin \& Alaggia, 2013). It is critical to include this expanded version in social work practice: "bio-psycho-social-cyber".

The implications of this expanded theory for practice were evident in participants' responses and are consistent with the recent theorizing and recommendations of social work scholars (Mattsion, 2012; Reamer, 2013). The practice wisdom to which participants came to based on their experiences is consistent with the clinical and ethical issues and recommendations in the literature. To address the clinical and ethical issues Reamer (2013) and Mattison (2012) concur that social workers must become familiar with and competent in managing the clinical and ethical issues related to ICT. They each recommend implementing an informed consent process, providing information to clients on such matters as appropriate topics to discuss through ICT, response times, and risks to privacy. In fitting with the bio-psycho-social-cyber world, 
implications include the need to ensure systematically that practitioners become familiar with ICT benefits and risks through their own reflection as well as through training and familiarity with evidence; and that they review ICT use with clients in setting the therapeutic frame.

The immediate responsiveness of ICT is pervasive in our society and invariably can affect client expectations about when the social worker will respond. A finding was that practitioners had become cognizant that while initial informed consent was important in setting the stage, it was not sufficient. An implication for practice is that throughout therapy, practitioners must expect to not only provide initial informed consent as recommended by Reamer (2013) and Mattison (2012), but must monitor and as needed, be explicit about the boundaries.

While the 'young and new' practitioners were all highly knowledgeable and dependent on ICT, there were differences among them. Some young practitioners' understanding of the scope and impact of ICT made them acutely aware of their own and their clients' vulnerability. These respondents used ICT innovatively but in a way that protected boundaries and privacy, such as maintaining "work" Facebook accounts. Others incorporated ICT into their practice in a way that mirrored their private lives, such as responding late at night or on Facebook. These behaviours are at odds with the cautionary messages in the literature regarding engaging with clients in social media such as Facebook or Twitter (Reamer, 2013), which must be addressed in a way that promotes good practice and open discussion. An implication for practice and education is that practitioners, supervisors, agency administrators and educators must become knowledgeable and engage in discussions about ICT use. As participating administrators observed, while acknowledging risks, it is important to encourage creative thinking as well as developing appropriate policies. Such discussion needs to take into account the context of the ever changing 
digital world and the evolving attempts to develop practice and polices that address clinical and ethical concerns and that make room for the potential benefits of ICT use with practice.

While the literature acknowledges benefits, the focus is on the risks and need for guidelines and standards of practice. Future research that examines the ways ICT can supplement face-toface practice in a beneficial and ethical manner will contribute knowledge for practice. To achieve this goal, it will be essential to obtain clients' perspectives. 


\section{References}

Author, 2012

Author, 2013a

Author, 2013b

Betteridge, L. (2012). Practice notes: communication technology and ethical practice: Evolving issues in a changing landscape. Ontario College of Social Workers and Social Service Workers Perspective, 11(2), 20-23. Retrieved from http://www.ocswssw.org/docs/practice_notesprivate_practice_fall_2012.pdf?LanguageID=EN-US

Blais, J., Craig, W.M., Pepler, D.J., \& Connolly, J. (2008). Adolescents online: The importance of Internet activity choices to salient relationships. Journal of Youth and Adolescence, 37(5), 49-58. doi: 10.1007/s10964-007-9262-7.

Boschen, M., \& Casey, L. (2008). The use of mobile telephones as adjuncts to cognitive behavioral psychotherapy. Professional Psychology: Research and Practice, 39(5), 546552. doi: 0.1037/0735-7028.39.5.546

Bradley, L.J., \& Hendricks, B. (2009). E-mail and ethical issues. The Family Journal: Counseling and Therapy for Couples and Families, 17(3), 267-271. doi: $10.1177 / 1066480709338293$

Bronfenbrenner, U. (1979). The ecology of human development. Cambridge, MA: Harvard.

Charmaz, K. (2006). Constructing grounded theory: A practical guide through qualitative analysis. Thousand Oaks, California: Sage Publications Inc.

Clough, B.A., \& Casey, L.M. (2011). Technological adjuncts to enhance current psychotherapy practices: a review. Clinical Psychology Review, 31, 279-292.

D’Arcy Jr, J.R., \& Stiles, W.B. (2009). Session impact and alliance in online text-based 
psychotherapy: Comparison to face-to-face therapy and influence of participant factors. New Research in Mental Health, 102. Retrieved from:

http://test-weirs.mh.state.oh.us/assets/research-evaluation/grants/new-researchvol18.pdf\#page $=118$

Eonta, A., Christon, L., Hourigan, S., Ravindran, N., Vrana, S., \& Southam-Gerow, M. (2011). Using everyday technology to enhance evidence-based treatments. Professional Psychology: Research and Practice, 42(6), 513-520. doi: 10.1037/a0025825

Epstein, J., \& Bequette, A. (2013). Smart phone applications in clinical practice. Journal of Mental Health Counseling, 35(4), 283-295.

Finn, J. (2006). An exploratory study of email use by direct service social workers. Journal of Technology in Human Services, 24(4), 1-20. doi: 10.1300/J017v24n04_01

Gitterman, A., \& Germain, C.B. (2008). The life model of social work practice: Advances in theory \& practice $\left(3^{\text {rd }}\right)$. New York, NY: Columbia University Press.

Johnson, G.M. (2010). Internet use and child development: The techno-microsystem. Australian Journal of Educational \& Developmental Psychology, 10, 32-43.

Johnson, G.M., \& Puplampu, P. (2008). A conceptual framework for understanding the effect of the Internet on child development: The ecological techno-subsystem. Canadian Journal of Learning and Technology, 34, 19-28.

Holmes, C., \& Foster, V. (2012). A preliminary comparison study of online and face-to-face counseling: Client perceptions of three factors. Journal of Technology in Human Services, 30(1), 14-31. doi: 10.1080/15228835.2012.662848

Martin, J. (2013). Out of focus: Exploring practitioners' understanding of child sexual abuse 
images on the Internet. (Doctoral Dissertation). T-Space, University of Toronto Libraries, Toronto, Ontario.

Martin, J., \& Alaggia, R. (2013). Sexual abuse images in cyberspace: Expanding the ecology of the child. Journal of Child Sexual Abuse, 22(4), 398-415.

Mattison, M. (2012). Social work practice in the digital age: Therapeutic e-mail as a direct practice methodology. Social Work, 57(3), 249-258. doi: 10.1093/sw/sws021.

McCarty, D., \& Clancy, C. (2002). Telehealth: Implications for social work practice. Social Work, 47(2), 153-161. doi: 10.1093/sw/47.2.153

Menon, G.M., \& Miller-Cribbs, J. (2002). Online social work practice: issues and guidelines for the profession. Advances in Social Work, 3(2), 104-116. Retrieved from http://journals.iupui.edu/index.php/advancesinsocialwork/article/view/34

Migone, P. (2013). Psychoanalysis on the Internet: a discussion of its theoretical implications for both online and offline therapeutic technique. Psychoanalytic Psychology, 30(2), 281299. doi: $10.1037 / \mathrm{a} 0031507$.

Murphy, L., Parnass, P., Mitchell, D., Hallett, R., Cayley, P., \& Seagram, S. (2009). Client satisfaction and outcome comparisons of online and face-to-face counselling methods. British Journal of Social Work, 39(4), 627-640. doi: 10.1093/bjsw/bcp041

National Association of Social Workers (NASW) \& Association of Social Work Boards (ASWB). (2005). NASW \& ASWB Standards for technology and social work practice. Retrieved from http://www.socialworkers.org/practice/standards/naswtechnologystandards.pdf Patton, M.Q. (1990). Qualitative evaluation and research methods (2 ${ }^{\text {nd }}$ ed.). Newbury Park, CA: Sage Publications, Inc. 
Perron, B., Taylor, H., Glass, J., \& Margerum-Leys, J. (2010). Information and communication technologies in social work. Advances in Social Work, 11(1), 67-81. Retrieved from http://deepblue.lib.umich.edu/bitstream/handle/2027.42/78034/46.pdf;jsessionid=99D502 2CBF1037EB371F871589B199F1?sequence=1

Reamer, F. (2013). The digital and electronic revolution in social work: Rethinking the meaning of ethical practice. Ethics and Social Welfare, 7(1), 2-19. doi:

$10.1080 / 17496535.2012 .738694$

Rummell, C.M., \& Joyce, N.R. (2010). "So wat do u wan to wrk on 2day?”: The ethical implications of online counseling. Ethics and Behavior, 20(6), 482-496. doi: $10.1080 / 10508422.2010 .521450$

Santhiveeran, J. (2004). E-therapy: Scope, concerns, ethical standards, and feasibility. Journal of Family Social Work, 8(3), 37-54. doi: 10.1300/J039v08n03_03

Santhiveeran, J. \& Grant, B. (2006). Use of communication tools and fee-setting in e-therapy. Social Work in Mental Health, 4(2), 31-45. doi: 10.1300/J200v04n02_03

Wright, J. (2002). Online counseling: Learning from writing therapy. British Journal of Guidance and Counselling, 30(2), 285-298. doi: 10.1080/030698802100002326 